\title{
TREINAR FUTEBOL RESPEITANDO A ESSÊNCIA DO JOGO: O EXEMPLO DO SALTO COMO AÇÃO TÁTICA E NÃO SOMENTE TÉCNICO-FÍSICA
}

Pedro Miguel Silva

Pedro Manuel de Oliveira Santos

Nelson Kautzner Marques Junior

\section{Resumo}

O objetivo da revisão foi de exemplificar a metodologia de treino do salto de impulsão vertical no futebol assente em premissas táticas. O treino das capacidades físicas, desprovido da sua relação com o verdadeiro significado do Futebol, tem sido bastante utilizado nos últimos anos. Este tipo de trabalho esquece, frequentemente, a relação que deveria existir com o modelo de jogo do treinador, não maximizando a sua utilidade para a forma de jogar que se pretende cultivar na equipa. No caso do salto, este só existe no Futebol enquanto habilidade aberta, pertencente a um sistema termodinâmico de nãoequilíbrio, dentro do qual o jogador deverá tomar deliberada e oportunamente a decisão de saltar. Neste sentido consideramos oportuno estabelecer uma relação entre o treino do salto e o modelo de jogo.

\section{Palavras-Chave}

Futebol; Modelo de jogo; Salto de impulsão vertical; Periodização; Tática.

\section{COACHING FOOTBALL RESPECTING THE GAME'S ESSENCE: THE EXEMPLE OF JUMPING AS A TACTICAL SKILL AND NOT JUST TECHNICAL-PHYSICAL}

Pedro Miguel Silva

Pedro Manuel de Oliveira Santos

Nelson Kautzner Marques Junior

\begin{abstract}
The objective of this review was to justify the methodology of training vertical jump in soccer according to tactical aspects. Coaching football regarding only physical parameters is a coaching model that has been used often in the last years. Coaches frequently prescribe exercises that are not related with their pattern play. Vertical jump is used in soccer by players to respond to coaches' tactics and strategy, so we believe that there must be a connection between exercise prescription to improve vertical jump and the coaches' model of play. We believe that practicing exercises regarding only physical demands is not attempting the so desired coaching specificity in soccer.
\end{abstract}

\section{Key-Words}

Soccer; Game model; Vertical jump; Periodization; Tactical. 


\section{INTRODUÇÃO}

O salto de impulsão vertical aparece no futebol sob a forma do cabeceio ou na técnica do salto do goleiro para realizar a defesa ou na saída do gol. Poderá também surgir apenas como uma forma de pressionar ou dificultar a ação do jogador adversário que vai cabecear a bola. O salto de impulsão vertical aparece no treino e no jogo com grande evidência. De acordo com Oliveira, Amorim e Goulart (2000), o número de saltos de impulsão vertical durante um jogo de futebol varia conforme a função do jogador ( 9,5 para os defensores, 6 para os meio-campistas e 19,5 vezes para os atacantes). Porém, de acordo com a importância da partida, as características das equipes, o país onde se desenvolve o jogo e outros, a quantidade de saltos de impulsão vertical tende diferir dos valores dos pesquisadores anteriores, Rahnama, Reilly e Less (2002) encontraram em 10 jogos um total de 1723 cabeceios. Marques Júnior (2004) afirmou que os jogadores fazem durante as partidas uma quantidade de 5 a 14 cabeceios. Muito desses cabeceios podem resultar em sucesso ofensivo (PAPADIMITRIOU et al., 2001). Geralmente ocorre dentro da área (RAMOS; OLIVEIRA JUNIOR, 2008). Para alguns autores, essa análise do jogo referente o volume de cabeceios é um indicador para a prescrição do treinamento (BLOOMFIELD; POLMAN; O`DONOGHUE, 2007; BRAZ; BORIN, 2009).

Esta quantificação dos componentes técnicos servirá apenas para que o técnico tenha uma referência do número de ações que são utilizadas no jogo (REILLY, 2001). Essa análise é meramente quantitativa não informa em qual situação da partida ocorre o cabeceio, outro problema, não determina o setor do campo onde aconteceu a jogada e por qual motivo foi efetuado esse fundamento. Este fato constitui-se como um forte indicador da complexidade do jogo de futebol. Mas muitos técnicos prescrevem os números do cabeceio durante um circuito (ESPOSITO et al., 2004), na sessão de força reativa (GAUFFIN; EKSTRAND; TROPP, 1988), no treino técnico de cabeceio e no treino situacional desse fundamento (LEAL, 2001). Apesar dessa estrutura de treino, essa sessão está desprovida da sua relação com o verdadeiro significado do futebol, não se preocupa em treinar o cabeceio conforme o modelo de jogo da equipe (BATISTA, 2006). A escolha dos exercícios que objetivem o treino do salto, só tem sentido partindo da premissa que o enquadra enquanto ação tático-técnica concreta ao critério já que, ao contrário do que se passa noutras modalidades, aqui não há necessidade onde, o atleta que salta mais alto é, efetivamente, aquele que tem a melhor performance durante o cabeceio, resultando em um gol ou afastando o perigo da área. Esse tipo de treino sem estar conforme o modelo de jogo, comum no treino

Conexões: revista da Faculdade de Educação Física da UNICAMP, Campinas, v. 7, n. 2, p.38-63, maio/ago. 2009. 
físico e/ou técnico de cabeceio migrou do desporto individual para o futebol (GAYA; TORRES; BALBINOTTI, 2002), tornando inadequado, mas infelizmente é muito prescrito.

Treinar o cabeceio conforme o modelo de jogo e ao mesmo tempo se preocupar com o salto de impulsão vertical não é uma atividade indicada na maioria das sessões do futebol (COMETTI, 2002; WILLIAMS; HODGES, 2005), essa metodologia difere da maioria dos trabalhos efetuados no futebol, sendo evidenciado na literatura desse desporto (BANGSBO; MOHR; KRUSTRUP, 2006; REILLY; GILBOURNE, 2003). Entretanto, essa maneira de treinar o cabeceio do futebol é comum na periodização tática (BATISTA, 2006). Para alguns autores o treino do futebol só é adequado se ocorrer no jogo ou no treino situacional (FREIRE SILVA; DE ROSE JUNIOR, 2005; GRAÇA; MESQUITA, 2007; LEITÃO, 2008), mas sendo praticado de acordo com o modelo de jogo (CAMPOS, 2007). Treinar o cabeceio de acordo com o modelo de jogo torna-se vantajoso porque é exercitada a técnica numa situação problema da partida e ao mesmo tempo o atleta trabalha a tática no momento do jogo. Esse tipo de treino é recomendado por vários especialistas no ensino dos jogos desportivos coletivos (COSTA; NASCIMENTO, 2004; LEONARDO; SCAGLIA; REVERDITO, 2009; KRÖGER; ROTH, 2002).

Durante a execução do cabeceio a memória de procedimento é mais solicitada, enquanto que a memória declarativa atua no pensamento tático a fim de resolver a situação problema da jogada e para o atleta realizar suas ações conforme o modelo de jogo da equipe (GRECO, 2006). Então, o tipo de treino ocasiona uma plasticidade neural própria para aquela tarefa (JENSEN; MARSTRAND; NIELSEN, 2005), a sessão centrada na partida e de acordo com o modelo de jogo permite que as adaptações neurais sejam conforme o jogar (GOMES, 2006). Fato que não ocorre com o treino técnico de cabeceio porque a memória mais solicitada é a de procedimento, o atleta vivência apenas a biomecânica da cabeçada e não trabalha a ação desportiva num contexto da partida (GARGANTA, 2002). Por esse motivo que a metodologia de treino da periodização tática é adequada para os jogadores do futebol. A periodização tática possui uma metodologia de treino pouco conhecida no mundo, ela é difundida na cidade do Porto, em Portugal, precisamente na Universidade do Porto e um dos técnicos portugueses que utiliza esse modelo de periodização é José Mourinho (GAITEIRO, 2006), atualmente no Inter de Milão. No Brasil a periodização tática começou a ser divulgada através dos trabalhos de Marques Júnior (2006, 2007, 2009) e outros autores, como Leitão (2008). Neste tipo de periodização a tática é a componente central (SANTOS, 2006), enquanto que as outras variáveis (físico e técnica) lhe estão subordinadas. O objetivo da revisão foi de exemplificar o treino do salto de impulsão vertical, considerando-o uma ação tática de Conexões: revista da Faculdade de Educação Física da UNICAMP, Campinas, v. 7, n. 2, p.38-63, maio/ago. 2009. ISSN: 1983-930. 
jogo, e portanto precedente de uma tomada de decisão relacionada com uma forma de jogar, e não somente um gesto técnico-físico desprovido de significado contextual.

\section{CIÊNCIA}

A ciência, ao impor a neutralização e o isolamento do sujeito como critério de cientificidade, neutralizase e isola-se, por extensão, a ela própria, aprisionando-se naquela que tem constituído a sua mais incômoda e irresolúvel armadilha tautológica. Na procura quase obsessiva de objetivar o objeto de estudo, a ciência corre o risco de implicar numa condição de tal distância e exterioridade que conflite com a representação objetiva da prática (GARGANTA, 2001). Por mais prático que seja o técnico, costuma adorar o rigor quantitativo e não pode viver sem ele (MAGUEIJO, 2003). Depara-se frequentemente com um cientificismo que penaliza a subjetividade e desencoraja a abordagem qualitativa em nome duma objetividade e de um pseudo-rigor que frequentemente se enredam numa teia de erros de paralaxe (TURATO, 2003).

"Os modos simplificadores do conhecimento mutilam mais do que exprimem as realidades ou os fenômenos que relatam", dando lugar a uma nova ignorância ligada ao desenvolvimento da própria ciência, a uma inteligência cega que destrói os conjuntos e as totalidades, que isola todos os objetos daquilo que os envolve (MORIN, 1990). O treino do salto de impulsão vertical no futebolista deverá obedecer a determinados princípios nos quais se encontrem subjacentes o respeito pela complexidade do fenômeno futebol, e nos quais a totalidade dos conjuntos e dos sistemas não seja reduzida a parcelas (fatorização) para posterior interação. Parece emergir uma nova realidade metodológica para o futebol, em que o jogo de futebol, entendido como uma complexidade, é irredutível a soma das partes (TAMARIT, 2007).

Urge a necessidade de assumir um novo paradigma científico, o paradigma da complexidade, que encare a realidade com uma visão unificadora, que afaste a noção cartesiana na qual "a inteligência parcelada, compartimentada, mecanicista, disjuntiva, reducionista, rompe o complexo do mundo em fragmentos disjuntos, fraciona os problemas, separa o que está enlaçado, unidimensional o multidimensional" (CARVALHAL, 2001). Afastemo-nos do paradigma da simplificação que controla a aventura do pensamento ocidental desde o séc. XVII, permitindo grandes progressos do conhecimento científico e da reflexão filosófica embora as conseqüências nocivas só comecem a revelar-se no séc. XX. 
O salto, entre muitas outras ações tático-técnicas, aparece no jogo de forma imprevisível e não préprogramada (SCAGLIA, 2003). Não é desejável conceber o salto no futebol (assim como qualquer outra ação tático-técnica) através de uma perspectiva exclusivamente técnica ou exclusivamente física, nem sequer mesmo exclusivamente físico-técnica. Este não pode ser considerado como um gesto técnico isolado, num sistema fechado. O futebol é um sistema aberto e esta noção deve emergir nos seus diferentes estudos, sabendo-se a priori que "no futebol não é possível estandardizar as ações dos jogadores e muito menos a sua sequência" (GARGANTA, 1999).

Segundo Santos, Silva e Jardim (2004), da noção de sistema advêm de uma unidade complexa, um todo que não se reduz a soma das suas partes constituintes. O sistema aberto está na origem de uma noção de termodinâmica cuja existência e cuja estrutura depende de uma alimentação exterior, não apenas material/energética, mas também organizacional/informacional. No jogo "as equipes funcionam num registro de uma termodinâmica do não-equilíbrio, pois só assim é possível desenvolver mecanismos de auto-organização que criem estruturas e sentidos a partir da aleatoriedade. (...) As equipes são "estruturas dissipativas" na medida em que se desenvolvem longe-do-equilíbrio" (GARGANTA; CUNHA; SILVA, 2000). Segundo Morin (2003), um sistema fechado está em estado de equilíbrio e o futebol enquanto sistema aberto implica um "desequilíbrio do fluxo energético que o alimenta, e, sem esse fluxo, haveria desregulação organizacional provocando rapidamente enfraquecimento". De acordo com Santos, Silva e Jardim (2004), este autor refere que num primeiro sentido, o desequilíbrio que alimenta permite ao sistema manter-se em aparente equilíbrio, quer dizer, em estado de estabilidade e de continuidade, e este aparente equilíbrio só pode degradar-se se for abandonado a ele próprio, ou seja, se houver fecho do sistema. Refere ainda que neste estado, firme, constante e no entanto frágil - steady-state - as estruturas permanecem as mesmas, mas os constituintes são mutáveis.

Assim, a ciência no futebol deverá ter o objetivo de não matar o jogo de futebol, nem de capar propriedades da sua natureza, evitando que as componentes mais belas do jogo se amenizem estudo após estudo. O salto não é apenas uma ação motora levada a cabo pelos vários músculos intervenientes de acordo com um padrão motor considerado mais eficiente. Ele é, para além de uma perspectiva biológica e/ou técnico-analítica, uma ação táctica, e esta deverá ser a dimensão mais importante do futebol, a qual o rigor e o determinismo absoluto dos métodos científicos, postulados da perspectiva cartesiana, não poderão dar respostas. A verdadeira contribuição da ciência para o futebol dependerá de uma perspectiva filosófica de entender sistemas termodinâmicos e complexos (onde se inclui o futebol) caracterizados 
pela sua complexidade, adaptabilidade, auto-organização e constante alternância entre ordem e caos (WALDROP, 1992).

\section{ORDEM VERSUS CAOS: A IMPREVISIBILIDADE NO JOGO DE FUTEBOL}

Não existe nenhum treinador que não pretende conseguir prever com uma certeza infinitesimal a evolução do jogo, controlar esse sistema multivariável. Por isso talvez ele preferisse substituir a variabilidade pela estereotipia na expectativa de que as atitudes dos seus jogadores fossem previstas e articuladas com máxima certeza, de que as propriedades topológicas do movimento que eles manifestam fossem as menos variáveis. Ele deve, no entanto, aperceber-se que a máxima estereotipia, correspondendo a mínima variabilidade, corresponde também, a mínima adaptabilidade (GARGANTA; CUNHA; SILVA, 2000).

No jogo de futebol "em muitos casos, a ordem parece nascer do caos" (LEBED, 2006). Não raramente, situações aparentemente lógicas e corretas geram resultados negativos, e ações aparentemente ilógicas ou incorretas produzem resultados satisfatórios, o que significa que, não obstante a vontade unânime de todos os jogadores envolvidos numa partida, os comportamentos dos jogadores que procuram a todo o custo ganhar, ou não perder, podem acarretar consequências incontroláveis para a equipe (GARGANTA, 2001).

O universo está submetido a dois princípios opostos: ordem e desordem (MORIN, 1997). Este tipo de acontecimento caótico está bem presente no futebol. Joga-se na fronteira entre o caos e a ordem, onde em muitos casos a ordem parece nascer do caos. Consoante o tipo de perturbação aleatória que o sistema sofre, no momento em que se torna instável, surge um outro tipo de organização, provocando o aparecimento espontâneo de estruturas que apresentam uma certa ordem (GARGANTA, 2000). No futebol não é possível estandardizar as ações dos jogadores e muito menos a sua sequência (GARGANTA, 1999). É impossível que um treinador preveja o momento em que um dos seus jogadores vai realizar um salto e que preveja o número de saltos que poderão ocorrer durante um jogo. Neste sentido, os estudos orientados por normas científicas no intuito de prever ou estimar o número de saltos que executam os futebolistas, têm a sua grande relevância na quantificação da sua ocorrência no futebol, no tipo de ação tático-técnica bem como a importância a ser contemplada no processo de treino, (mas, evitando neste, uma abordagem linear e determinista - tal como é requerido pela atual visão cartesiana da ciência).

Conexões: revista da Faculdade de Educação Física da UNICAMP, Campinas, v. 7, n. 2, p.38-63, maio/ago. 2009. 
$\overline{\text { Segundo Garganta; Cunha e Silva (2000), um sistema caótico pode ser isoladamente imprevisível, }}$ mas globalmente estável. Nesta situação irrompem padrões que denunciam o comportamento caótico, a pequena escala, mas, a grande escala, denunciam uma certa regularidade. Estes autores sugerem que quando a dinâmica é caótica surge a necessidade de ultrapassar a abordagem analítica, centrada na causa/efeito, e centrar na descrição qualitativa dos padrões de comportamento. Isto prende-se com o tipo de estímulo que é usado no treino para que os jogadores executem o salto. Deve-se privilegiar o tipo de estímulo (qualidade) em detrimento do número de estímulos (quantidade). Também no treino o estímulo deve ser preferencialmente imprevisível e aleatório obedecendo as características do futebol, e mais concretamente, as características do modelo de jogo do treinador, o que permitirá afastar o nosso futebol de um caráter abrangente mais abstrato (SANTOS, 2006). O processo de treino não deve ser sempre imposto de forma simplista e linear numa relação de causa-efeito (por exemplo, ao apito o jogador salta 3 barreiras e retoma o seu lugar na fila) (GARGANTA, 2002). Durante as diversas fases do jogo, é provável que os jogadores tenham de realizar saltos de impulsão vertical para conseguirem os seus objetivos, no entanto estes surgem, ou não, em função das circunstâncias desenvolvidas pelo nosso jogo, e deverá também ser assim que terá de aparecer no treino (LEITÃO, 2008b).

Treinar o salto de impulsão vertical baseado apenas em valores quantitativos sem se preocupar com a situação de jogo ocasiona adaptações neurais próprias para esse trabalho, não preparando o atleta para a partida. Simplesmente exercita a técnica do cabeceio e a força reativa dos membros inferiores para o futebolista efetuar o salto (MARTINS; GARGANTA, 2003). Atletas que treinam com ênfase na técnica possuem pensamento tático inferior aos jogadores onde a sessão é centrada no jogo (PÉREZ MORALES; GRECO, 2007). Então, esses esportistas para resolverem as situações problemas da partida costumam ser inferiores aos jogadores onde a prioridade é treinar durante a partida (RAAB; MASTERS; MAXWELL, 2005). Isso ocorre por causa da plasticidade neural (mudanças ocorridas no sistema nervoso central) (AZOUZ, 2005), a especificidade do estímulo desencadeia mudanças nos circuitos neurais, neuroquímicos e metabólicos-corticais referentes ao tipo de treinamento, desencadeando o armazenamento na memória de longo prazo (FERRARI et al., 2001). Portanto, o treino do salto de impulsão vertical centrado no jogo, segue o princípio da especificidade, conforme Tubino e Moreira (2003) determinaram, e ainda gera adaptações neurais, referentes à memória de longo prazo, própria para a situação da partida e de acordo com o modelo de jogo (GOMES, 2006). 


\section{MODELO SISTÊMICO}

Tradicionalmente, na abordagem do processo de treino do futebol, encontram-se descritos na literatura, quatro componentes do rendimento desportivo: tática, técnica, físico e psicológico (TELES, 2007). A perspectiva mais recente assume de uma forma unificadora e não reducionista (BRAZ, 2006). O pensamento de Maguejo (2003) seguiu essa idéia: "ao contemplar o todo (leia-se os componentes de rendimento unificados), vemos que, tal qual cada um de nós, o universo (leia-se jogador/equipe enquanto sujeitos multidimensionais) é muito mais que o mecanismo que governa as partes que constituem o todo".

De acordo com Frade (1985) "a ordem ou organização de um todo ou sistema transcende aquilo que pode ser "oferecido" pelo conjunto das suas partes, quando estas são consideradas isoladas umas das outras." Neste sentido, não se pode isolar as componentes do rendimento sob pena de amputarmos o processo de treino (se bem que seja impossível prever e controlar o comportamento do jogador segundo o rigor científico, integrando todas as variáveis) (CARVALHAL, 2001). Treinar de forma exclusivamente analítica (entenda-se isolada) o salto de impulsão vertical implica perder de vista a importância desta ação no jogo (RÉ; BARBANTI, 2006). Isto faz os treinadores de saltos e não treinadores de futebol. Não podese deixar de equacionar a noção globalizante do conjunto, do sujeito multifacetado, que responde em todas as situações com a sua essência total. Os componentes de rendimento são uma abstração, um mero entendimento da realidade agregada segundo uma perspectiva simplista. Os treinadores precisam relacionar com os componentes de rendimento de uma forma articulada. Não devem falar de decompor, mas em modelar.

A modelação sistêmica permite o tratamento de fenômenos complexos sem que seja necessária a sua decomposição analítica (MOIGNE, 1994). Permite conceber o treino focando sem reduzir, olhando para a "parte" sem perder de vista a complexidade do "todo" e a sua relação complexa com este. Assim, de acordo com Tavares e Frade (2003), "a modelação da complexidade permite aos jogadores interessados entenderem-na, constituindo-se a sua inteligência intencional", pois só a ação intencional é educativa. A inteligibilidade de um sistema complexo deve ser modelado sistemicamente.

Focar o objeto de estudo apenas numa perspectiva do esforço físico ou da preparação física, empobrece a inteligibilidade do conhecimento construído pela interação deliberada destes conceitos. É necessário um conceito menos singular e mais geral de interatividade (interações todo-parte e parte-partes). A esta alternativa "reducionismo - interação" corresponderá uma alternativa "decomposição - articulação" 
(MOIGNE, 1994). De acordo com Morin (1999), para pensar localmente é necessário pensar globalmente, e para pensar globalmente é necessário pensar localmente.

Uma primeira abordagem para contextualizar o treino do salto de impulsão vertical passa por um conhecimento mais microscópico (pensamento local). O conhecimento das características anatofisiológicas e neuromusculares dos membros inferiores permite ao técnico construir mais eficazmente e com mais segurança exercícios de treino com vista ao desenvolvimento desta ação táticotécnica. No entanto, o princípio deverá ser o da "decomposição - articulação", sem nunca perder a visão global do fenômeno (pensamento global). A interação "todo - parte" e "parte - partes" deverá orientar todo o processo. Desta forma, a contribuição das ciências da vida só poderá ser equacionada numa perspectiva sistêmica e nunca parcelar. Devemos desenvolver em nós próprios a aptidão para contextualizar e globalizar os saberes criando um laço indissolúvel entre as ciências da vida e as ciências humanas (MORIN, 1999).

\section{TÁTICA: O COMPONENTE MAIS IMPORTANTE}

Alguns autores referem que não basta que se desenvolvam os componentes de rendimento de uma forma integral, destacando-se a necessidade de se elaborar um modelo de treino capaz de fazer frente a toda a problemática conceitual e metodológica inerente ao jogo de futebol (MARTINS; GARGANTA, 2003).

Garganta, Maia e Marques (1996) afirmaram que existe uma necessidade de construção de um corpo de conhecimentos ao nível do ensino, treino e da competição em futebol na qual a matriz organizacional deve considerar a tática como núcleo diretor, Garganta (1997) informou que é através destes comportamentos que ocorrem durante uma partida são consubstanciados. É ela que dá coerência construtiva aos comportamentos, as interações dos jogadores e que confere ou retira sentido a sua atividade durante o jogo (GARGANTA, 1999). A educação tática dos futebolistas é o elemento mais importante para uma equipe ter sucesso (GARGANTA; GRÉHAIGNE, 1999).

Oliveira e Frade (1991) salientaram que o componente "físico" assume um papel igualmente importante, mas sempre condicionado pelas exigências "tático-técnicas" e de "tática-individual". Este componente "físico", segundo estes autores, surge em paralelo com a tática (tático-técnica e tática-individual), mas sempre por arrastamento, o que indica que a estruturação do componente "físico" está referenciada ao esforço específico, não do futebol em geral (abstrato), mas do futebol referenciado ao modelo de jogo adotado. Deve haver preocupação durante todo o momento em tornar presente as premissas do técnico, 
ou seja, a filosofia de jogo. Neste sentido, o treino do salto também deve ser contextualizado no modelo de jogo do treinador. Os tradicionais exercícios de salto em profundidade ou os exercícios de agachamento balístico na sala de musculação estão desprovidos do específico-sistêmico que tanto são procurados no treino de futebol. Estes exercícios também são importantes, dependendo da fase da temporada, do tipo de sessão ou da finalidade dos próprios exercícios, no entanto a sua importância estará sempre dependente da importância que o treinador lhe atribuir, e de uma forma mais particular, da sua real importância com aquilo que se passa no nosso jogo que é o requerido pelo modelo de jogo.

Então, o treino do salto de impulsão vertical deve ser prescrito durante o jogo, precisamente, conforme o modelo de jogo adotado pelo técnico (BRAZ, 2006; LEITÃO, 2004). Não adianta apenas prescrever o salto de impulsão vertical durante o jogo se o atleta não tiver praticando essa sessão de acordo com o modelo de jogo (OLIVEIRA et al., 2006). A idéia central desse trabalho é a tática (OLIVEIRA, 2005), merecendo que o ato do cabeceio esteja conforme a maneira de jogar da equipe, ou seja, o modelo de jogo (OLIVEIRA, 2007). Portanto, treinar o cabeceio de acordo como a equipe vai jogar necessita de uma sessão na partida ou no treino situacional (FILGUEIRA; GRECO, 2008) para ocorrer o armazenamento do conteúdo na memória de longo prazo (ROBERSTSON; PASCUAL-LEONE; MIALL, 2004).

\section{TREINO DO SALTO NO FUTEBOLISTA E MODELO DE JOGO DO TREINADOR: UMA ABORDAGEM MAIS COMPLEXA (ENTENDA-SE ESPECÍFICA)}

De acordo com Graça (1994), são duas ordens de problemas que estão implicadas no processo de aprendizagem (entenda-se treino): (1) os problemas da seleção da resposta adequada a situação (o quê, o quando e o porquê) e os problemas relativos a realização da resposta motora (o como). Faria e Frade (1999) explicaram que "[...] no futebol não ganha quem salta mais alto, quem corre durante mais tempo ou quem é mais rápido. Normalmente o objetivo do jogo de futebol é ser superior ao adversário em número de gols, ou seja, marcar mais e sofrer menos [...] Certamente que o mais importante não é a componente físico, mas o componente tático da periodização". Outros autores concordaram com essas afirmações (GASPAR; FERREIRA; PÉREZ, 2005; GRÉHAIGNE; GODBOUT; BOUTHIER, 2001; NUNES; FANTATO; MONTAGNER, 2006; RINK; FRENCH; TJEERDSMA, 1996). Desta perspectiva de treino, torna-se evidente que, mais importante do que tentar melhorar a altura do salto dos futebolistas é melhorar a sua capacidade de decisão em relação ao "quando" e "como" saltar, ou seja, melhorar a sua capacidade de realizar o salto num qualquer momento do jogo de forma deliberada e oportuna. O modelo 
de jogo imposto pelo treinador condicionará fortemente as decisões dos jogadores, onde devem ou não estar, onde deverão colocar-se para saltar, ou como deverão cabecear.

O princípio da especificidade preconiza que sejam treinados os aspectos que se prendem diretamente com o jogo (estrutura do movimento, tipo de esforços, natureza das tarefas, (...) no sentido de viabilizar a maior transferência possível das aquisições conseguidas no treino para o contexto específico do jogo (GARGANTA, 1999). Desta forma o modelo de jogo e seus princípios ${ }^{1}$ enquanto conceito teórico assume grande relevância na orientação do processo de treino. Modelo de jogo e especificidade articulam-se de uma forma simbiótica nos jogos desportivos coletivos e, particularmente, no futebol.

Damásio (2001) informou que as imagens mentais "são construções momentâneas, tentativas de réplica, de padrões que já vivenciados pelo menos uma vez e para os quais a possibilidade de se obter uma réplica exata é baixa [...] a probabilidade de ocorrer uma réplica substancial pode ser superior ou inferior, dependendo das circunstâncias em que as imagens foram assimiladas e estão a ser acedidas." Se o técnico pretende que a equipe reveja um modelo de jogo que o treinador deseja, durante a competição, a prescrição das sessões não podem se basear em estímulos que estereotipam os tipos de imagens, sob pena do responsável pela sessão de reduzir substancialmente a diversidade de imagens que a equipe poderá assimilar. Por exemplo, prescrever demasiadamente o treino técnico e exigir dos futebolistas um modelo de jogo de alta complexidade durante a competição (GARGANTA, 1998). Uma sessão com ênfase na técnica prepara o jogador para executar bem o fundamento naquele contexto de treino (DAOLIO, 2002), mas não melhora o atleta para praticar o mesmo fundamento numa situação de jogo (TURNER; MARTINEK, 1995), não treinando o modelo de jogo elaborado pelo treinador.

Ainda de acordo com Damásio (2001), uma grande parte do conhecimento geral é armazenado no encéfalo sob a forma de imagens. Assim, as imagens sobre as quais o ser humano raciocina não só devem estar em foco como também devem ser mantidas ativamente na mente - algo que é realizado pela memória em constante trabalho através do treino. O mesmo autor refere que "o fato de um organismo possuir uma mente significa que ele forma representações neurais que podem tornar em imagens que são

\footnotetext{
${ }^{1}$ Segundo Oliveira (2003) o modelo de jogo representa uma idéia sobre o jogo baseada em princípios de jogo e seus derivados (sub-princípios) no que se refere as quatro fases do jogo de futebol: organização ofensiva, organização defensiva, transição defesa-ataque e transição ataque-defesa. Representa um pressuposto para o jogo e como tal está sempre em reconstrução, nunca se dando por concluído. O modelo de jogo adotado parte da idéia de jogo do treinador (concepção de jogo) e dos comportamentos que quer que a sua equipe/jogadores manifestem (individual e coletivamente) bem como no conhecimento que o treinador tem dos seus jogadores, capacidades e características especificadas de cada jogador e do nível de entendimento e conhecimento que eles têm do jogo. Os princípios de jogo representam um conjunto de características, comportamentos e padrões de comportamentos que o técnico pretende que a equipe/jogadores revelem durante diferentes momentos do jogo. Ao articularem-se entre si, os comportamentos e padrões de comportamento identificam uma identidade de equipe denominada de organização funcional. Esta não deve ser indutora de limitações individuais ou coletivas, mas produtora de comportamentos criativos balizados pela lógica dos padrões de comportamento que o treinador entende como relevantes.
}

Conexões: revista da Faculdade de Educação Física da UNICAMP, Campinas, v. 7, n. 2, p.38-63, maio/ago. 2009. 
manipuladas num processo chamado pensamento, o qual acaba por influenciar o comportamento em virtude do auxílio que confere em termos de previsão do futuro, de planificação deste de acordo com essa previsão e da escolha da próxima ação". Refere ainda que ao utilizar as imagens evocadas, pode recuperar um determinado tipo de imagem do passado, a qual foi formada quando ele planejar qualquer coisa que ainda não aconteceu, mas que espera que venha a acontecer. De acordo com esta perspectiva, quanto mais "rico" for o treino na diversidade de imagens induzidas aos jogadores/equipe, mais apto se tornará um jogador/equipe na sua capacidade de antecipar um estímulo (associando-o a uma imagem previamente adquirida) e de elaborar uma resposta/ação.

Um exercício deve possuir a faculdade de proporcionar aos jogadores/equipe o maior número de imagens para as tomadas de decisões serem adequadas na resolução do problema do jogo (TAVARES, 2002). Isto só será possível se o técnico utilizar exercícios que simulem situações de jogo ou que simulem aspectos relacionados com a organização do jogo da equipe (RAAB, 2003). É importante referir que, dentro desta diversidade de imagens o treinador deve procurar os exercícios que se relacionam com a maneira ou intenção de jogar da equipe, isto é, que derivem do modelo de jogo determinado pelo técnico (CARVALHAL, 2003). Castelo (1994) explicou que cada pessoa trás dentro da sua cabeça um modelo mental do mundo, uma representação subjetiva da realidade externa, que consiste em dezenas de milhares de imagens. "Mas para que a pessoa consiga agir... é indispensável que o modelo tenha alguma semelhança nas suas linhas gerais com a realidade [...]” (CASTELO, 1994). Assim, a especificidade deve traduzir-se na construção dos exercícios de treino, que procuram induzir nos jogadores a forma mais aproximada possível de pensar o jogo do treinador. Para tal os atletas não devem apenas treinar por treinar, mas sim treinar para tentar reduzir as diferenças entre aquilo que é a situação atual dos jogadores (a sua atual concepção do modelo de jogo do treinador) e aquilo para onde se quer que eles caminhem (o verdadeiro modelo de jogo do técnico). O treinador induz um pensamento coletivo nos jogadores através dos exercícios que seleciona. Estes deverão ser específicos uma vez que "proporcionam uma maior adaptação e geram um maior rendimento na prestação durante o jogo" (OLIVEIRA; FRADE, 1991).

$\mathrm{Na}$ seleção dos exercícios deve introduzir a noção de especificidade: "só se poderá chamar ESPECIFICIDADE a especificidade se houver uma permanente e constante relação entre as componentes psico-cognitivos, tático-técnicos, físicos e coordenativos, em correlação permanente com o modelo de jogo adotado e os respectivos princípios que lhe dão o corpo" (OLIVEIRA, 2005, 2007), ou seja, a adequabilidade/adaptabilidade de um exercício em função do modelo de jogo pretendido, 
articulando/modelando de forma sistêmica os 4 componentes do rendimento desportivo. Decorre também deste postulado a idéia que a especificidade se assume como um "conceito dinâmico e não absoluto e estático" (OLIVEIRA; FRADE, 1991).

Então, a elaboração dos exercícios do salto de impulsão vertical deve ocorrer no jogo ou no treino situacional (SINDIK; VIDAK, 2008; COUTINHO; SANTOS SILVA, 2009), mas estando de acordo com o modelo de jogo para acontecer um adequado trabalho tático (TRNINIC et al., 2008), a fim de proporcionar um armazenamento na memória a respeito do "o que fazer" e "como fazer" (WOLPERT; GHAHRAMANI; FLANAGAN, 2001). Caso essas diretrizes não sejam respeitadas o treino de salto de impulsão vertical não vai melhorar a inteligência de jogo do atleta (CARVALHAL, 2001), simplesmente desenvolverá o físico e/ou o técnico durante o cabeceio. Atividades que não exercitam o pensamento tático (RAAB, 2007). Barbanti (2001, p. 3) reforçou uma dessas afirmações, sobre o treino físico, de não estimular o raciocínio tático através da seguinte definição:

O treino físico é uma repetição sistemática de movimentos que produzem reflexos de adaptação morfológico e funcional, com o objetivo de aumentar o rendimento (físico) num determinado espaço de tempo.

Conclui-se que o treino de salto de impulsão vertical deve estar inserido no modelo de jogo da equipe de futebol para gerar a ação tática na partida indicada pelo treinador (OLIVEIRA et al., 2006).

\section{A CONSTRUÇÃO DOS EXERCÍCIOS}

Ao longo desse estudo de revisão foi defendido que "um exercício só é verdadeiramente específico se seguir uma orientação intimamente ligada ao modelo de jogo adotado pelo treinador, subjacente a um contexto que o define em determinado momento, fruto da lógica do processo de treino, atribuindo-lhe um sentido" (TAVARES; FRADE, 2003). Quando o técnico planeja o treino de acordo com esta ESPECIFICIDADE, o treino das capacidades físicas "força", "resistência" e "velocidade" assumem contornos diferentes de uma perspectiva estritamente fisiológica (científica). Assim, de acordo com os mesmos autores, podem-se dividir os exercícios por pacotes de tipos de contrações musculares, ou seja, atendendo a tensão, a velocidade de contração, a duração da contração, que serão determinados pelo propósito de jogar conforme uma maneira, o modelo de jogo. Deste modo, o treinador após verificar quais os comportamentos realizados no seu jogo que requisitam o tipo de contrações musculares que pretende treinar, deve solicitar esse tipo de comportamentos nos exercícios de treino.

Os saltos promovem a realização de grande tensão muscular e de contrações musculares excêntricas, baseadas na produção de força pelos músculos monoarticulares e sua transferências inter-segmentar pelos Conexões: revista da Faculdade de Educação Física da UNICAMP, Campinas, v. 7, n. 2, p.38-63, maio/ago. 2009. ISSN: 1983-930. 
músculos biarticulares dos membros inferiores, no sentido próximo-distal (DURWARD; BAER; ROWE, 2001; PRILUTSKY; ZATSIORSKY, 1994). Os saltos podem ser incluídos nas sessões de treino dedicadas ao treino de princípios, sub-princípios e sub-princípios dos sub-princípios do modelo de jogo caracterizados pelo uso de ações de "Força-Específica". Estes exercícios promovem alta tensão muscular, tem curta duração e apresentam uma velocidade moderada/alta (OLIVEIRA, 2004).

Deve prevalecer sempre a idéia de que as características físicas de determinado exercício surgem sempre por arrastamento daquilo que pretende ser o modelo de jogo, a maneira de jogar da equipe. É de acordo com o treino dos princípios, sub-princípios e sub-princípios dos sub-princípios do modelo de jogo do treinador que será dosada a dinâmica das cargas. Baseado nessa metodologia de treino, serão elaborados exercícios de treino que requeira, num determinado espaço de tempo definido, entre 9 a 30 dias porque Marques Junior (2009b) afirmou que essa duração acontece significativo armazenamento do conteúdo na memória, uma maximização das repetições do aspecto a que esteja a ser dada mais importância (neste caso treino do salto de impulsão vertical), sempre arrastado pela organização de jogo, ou seja, pelo trabalho tático.

De acordo com Tavares e Frade (2003), é necessário compreender que "existem diferentes 'futebois', diferentes jogos e diferentes formas de jogar [...]". Assim sendo, e tendo em mente a noção de ESPECIFICIDADE que foi apresentada anteriormente, torna-se impossível dar receitas para o treino, recomendar exercícios sob pena de estes se encontrarem fora da esfera do próprio modelo de jogo do leitor. O exercício só é específico se for construído pelo próprio treinador, de acordo com a sua forma de entender o jogo, de acordo com os seus princípios e filosofia. A própria forma de condução, na prática, de um mesmo exercício varia se mudar o treinador que o orienta, pois cada um foca determinados aspectos. Tudo se relaciona com a forma de entender o futebol e com as idéias que cada treinador possui. Não se pode portanto, sugerir nenhum exercício, mas apenas exemplificar, para um determinado sub-princípio de um hipotético modelo de jogo, um exercício no qual o salto de impulsão vertical é trabalhado de acordo com a noção de ESPECIFICIDADE. A seguir, são apresentados 4 exemplos de exercícios para o leitor entender como é estruturado o treino de salto de impulsão vertical centrado no modelo de jogo:

Exemplo $^{2} 1$

Tema / Momento ${ }^{3}$ :

\footnotetext{
${ }^{2}$ A representação do exercício foi organizada de acordo com o modelo de Oliveira (2003).

${ }^{3} \mathrm{O}$ exercício também pode ser organizado focando um momento defensivo.

Conexões: revista da Faculdade de Educação Física da UNICAMP, Campinas, v. 7, n. 2, p.38-63, maio/ago. 2009.

ISSN: 1983-930.
} 
$\checkmark$ Organização ofensiva intersetorial/grupal.

\section{Sub-Princípio:}

$\checkmark$ Organização ofensiva intersetorial/grupal - setor de meio-campo ofensivo e ataque: explorar os corredores laterais para efetuar cruzamentos para o cabeceio dos atacantes e meio-campistas; colocar rapidamente um grande número de jogadores em posição de cabeceio; colocar dois jogadores em posição adequada para efetuar o chute para a meta ( $2^{\mathrm{a}}$ bola).

Objetivos:

$\checkmark$ Explorar os corredores laterais;

$\checkmark$ Executar bons cruzamentos;

$\checkmark$ Procurar os espaços para o cabeceio e para a $2^{\text {a }}$ bola.

Forma/Descrição: $6+(2)$ x 5. A equipe atacante em azul de $6+(2)$ tenta colocar a bola nos seus laterais que efetuam o cruzamento para o cabeceio dos seus colegas de equipe. Os zagueiros em vermelho que se encontram a defender tentam impedir a equipe adversária de marcar o gol. Ninguém pode entrar na área delimitada para os laterais. Sempre que houver um gol ou uma interceptação, a bola recomeça no meiocampo pela equipe atacante. O espaço é o de um meio-campo, ou seja, acontece um treino situacional. Veja na Figura 1.

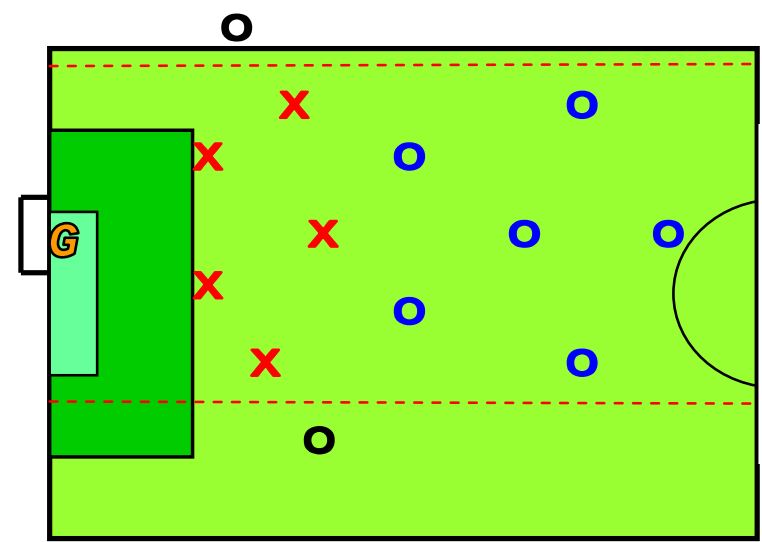

FIGURA 1: Os laterais em preto devem cruzar a bola para área para ocorrer o cabeceio, tendo um goleiro $(\mathrm{G})$.

\section{Exemplo 2}

Tema / Momento:

$\checkmark$ Organização ofensiva intersetorial/grupal.

\section{Sub-Princípio:}

$\checkmark$ Organização ofensiva intersetorial/grupal - setor de meio-campo ofensivo e ataque: baseado em Hughes e Franks (2005), as maiores chances de gol acontecem com quatro toques na bola, os jogadores deverão praticar dois passes, sendo que o terceiro toque o lateral vai efetuar um 
cruzamento para o cabeceio dos atacantes e meio-campistas, acontecendo o quarto contato com a bola durante o cabeceio.

Objetivos:

$\checkmark$ Aperfeiçoar a precisão do passe com poucos toques na bola;

$\checkmark$ Executar bons cruzamentos;

$\checkmark$ Procurar os espaços para o cabeceio.

Forma/Descrição: $6+(2)$ x 5. A equipe atacante tenta colocar a bola nos seus laterais que efetuam o cruzamento para o cabeceio dos seus colegas de equipe. Para a bola chegar nos laterais deve acontecer no máximo dois passes, o terceiro toque é o cruzamento para área e o quarto contato com a bola é o cabeceio dos atacantes ou meio-campistas. Os poucos toques na bola permitem que a defesa não tenha um adequado posicionamento, gerando um ataque veloz e com alta chance de gol. Os zagueiros que se encontram a defender tentam impedir a equipe adversária de marcar o gol. Ninguém pode entrar na área delimitada para os laterais. Sempre que houver um gol ou uma interceptação, a bola recomeça no meiocampo pela equipe atacante. $\mathrm{O}$ espaço de treino num meio-campo ofensivo, ou seja, acontece um treino situacional.

\section{Exemplo 3}

Tema / Momento:

$\checkmark$ Organização defensiva indi

$\checkmark$ vidual.

Sub-Princípio:

$\checkmark$ Antecipação e agressividade no duelo aéreo.

Objetivos:

Aperfeiçoar a técnica de intercepção da bola no ar.

Descrição:

$\checkmark$ Grupos de dois jogadores colocados um diante do outro e voltados para o treinador. O treinador lança uma bola para o ar e o segundo jogador, nas costas do primeiro, deve interceptar com a cabeça, antecipando-se ao seu colega que tenta dificultá-lo tentando ganhar a posição.

\section{Exemplo 4}

Tema / Momento:

$\checkmark$ Organização ofensiva coletiva.

Sub-Princípio:

$\checkmark$ Finalização com a cabeça em salto após entrada ao primeiro poste.

Conexões: revista da Faculdade de Educação Física da UNICAMP, Campinas, v. 7, n. 2, p.38-63, maio/ago. 2009. 


\section{Objetivos:}

$\checkmark$ Aperfeiçoar a técnica de finalização através de cabeceio;

$\checkmark$ Aperfeiçoar a técnica de passe/cruzamento.

\section{Descrição:}

$\checkmark$ Movimentação dos atacantes em vermelho do segundo para o primeiro poste em diagonal, para receber cruzamento e cabecear para gol (variar o lado do cruzamento). Veja na Figura 2.

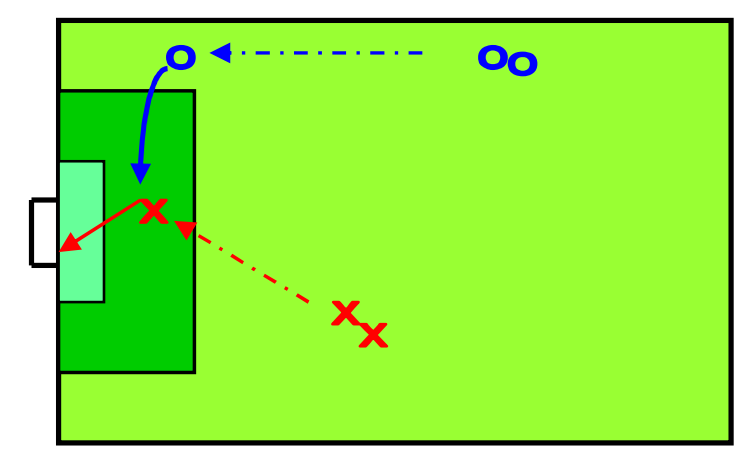

FIGURA 2: Os laterais em azul devem cruzar a bola para área ao primeiro poste para ocorrer o cabeceio pelos atacantes em vermelho.

\section{CONSIDERAÇÕES FINAIS}

Realizar prescrição do cabeceio apenas por valores quantitativos desse fundamento durante o treino técnico e/ou treino físico torna-se desprovido das características do futebol porque esse esporte acontece num contexto de imprevisibilidade onde a tática é o principal componente de rendimento dessa modalidade. Apesar de vários autores afirmarem que a tática é a variável mais determinante na performance do futebol (BATISTA, 2006; GARGANTA, 2002, 2006; MATTA; GRECO, 1996; SILVA et al., 2005; SILVA, 2006), atualmente o treino do cabeceio do futebol onde ocorre o salto de impulsão vertical, costuma ser elaborado fora da realidade do jogo. O grande problema dessa sessão é que gera adaptações neurais próprias para esse trabalho, não preparando o futebolista para o jogo. Porém, a metodologia de treino da periodização tática se preocupa como os conteúdos das sessões são armazenados na memória dos futebolistas, recomendando que o treinamento seja predominantemente tático, ou seja, o físico, o técnico e o psicológico vão estar subordinados a tática, precisamente ao modelo de jogo do treinador. Com essa perspectiva de treino, o salto de impulsão vertical é trabalhado no cabeceio conforme o modelo de jogo, ou seja, numa sessão estão inseridos todos os componentes de rendimento do futebol (físico, técnico, psicológico e tático). Então, a construção dos exercícios do salto de impulsão vertical terá que ser balizada pelo modelo de jogo. Mesmo quando o treinador deseja 
privilegiar um determinado aspecto físico num dado instante do treino, quem coordena a seleção do exercício (que deverá ter um impacto sempre nos 4 componentes do rendimento) é a organização de jogo, ou seja, o trabalho tático, onde, em última análise, os processos de tomada de decisão estão sempre presentes, integrados num contexto de modelação aberto (em função do sentido atribuído pela forma como o técnico elabora a maneira de jogar da sua equipe). O salto de impulsão vertical não foge a esta regra. Nesse sentido, o técnico deve recriar com uma determinada constância, a execução do salto de impulsão vertical em conformidade com o modelo de jogo.

\section{REFERÊNCIAS}

AZOUZ, A. Dynamic spatiotemporal synaptic integration in cortical neurons: neuronal gain, revisited. $J$ Neurophysiol, v. 94, n. 4, p. 2785-2796, 2005. Disponível em: www.jn.org. Acesso em: 04 jun. 2008.

BARBANTI, V. Treinamento fisico: bases científicas. 3. ed. São Paulo: CLR Balieiro, 2001.

BANGSBO, J.; MOHR, M.; KRUSTRUP, P. Physical and metabolic demands of training and match-play in the elite football player. $J$ Sports Sci, v. 24, n. 7, p. 665-674, 2006.

BATISTA, P. Organização defensiva: congruência entre os princípios, sub-princípios e sub-subprincípios de jogo definidos pelo treinador e sua operacionalização. Um estudo de caso no Sporting Clube do Espinho. Porto: Universidade do Porto, 2006.

BLOOMFIELD, J.; POLMAN, R.; O'DONOHUE, P. Physical demands of different position in FA Premier League soccer. J Sports Sci Med, v. 6, n. 1, p. 63-70, 2007. Disponível em: www.jssm.org. Acesso em: 10 fev. 2008.

BRAZ, T.; BORIN, J. Análise quantitativa dos jogos de uma equipe profissional da elite do futebol mineiro. Rev Educ Fis/UEM, v. 20, n. 1, p. 33-42, 2009. Disponível em: http://periodicos.uem.br/ojs/index.php/RevEducFis. Acesso em: 19 maio 2009.

BRAZ, J. Organização do jogo e do treino em futsal. 2006. Mestrado (Dissertação) - Faculdade de Ciências do Desporto e Educação Física, Universidade do Porto, Porto, 2006.

CAMPOS, C. A singularidade da intervenção do treinador como sua "impressão digital" na... justificação da periodização tática como uma "fenomenotécnica". Porto: Universidade do Porto, 2007.

CARVALHAL, C. No treino de futebol de rendimento superior: a recuperação é... muitíssimo mais que recuperar. Braga: Liminho, 2001.

Conexões: revista da Faculdade de Educação Física da UNICAMP, Campinas, v. 7, n. 2, p.38-63, maio/ago. 2009. 
. Periodização tática: a coerência entre o exercício de treino e o modelo de jogo adotado. Lisboa: FMH, 2003.

CASTELO, J. Futebol: modelo técnico-tático do jogo. Cruz Quebrada: Faculdade de Motricidade Humana, 1994.

COMETTI, G. La preparación física en el fútbol. Barcelona: Paidotribo, 2002.

COSTA, L.; NASCIMENTO, J. O ensino da técnica e da tática. Rev Educ Fís/UEM, v. 15, n. 2, p. 49-56, 2007. Disponível em: http://periodicos.uem.br/ojs/index.php/RevEducFis. Acesso em: 20 jan. 2008.

COUTINHO, N.; SANTOS SILVA, Conhecimento e aplicação de métodos de ensino para os jogos esportivos coletivos na formação profissional em Educação Física. Mov, v. 15, n. 1, p. 117-144, 2009. Disponível em: www.seer.ufrgs.br/index.php/index. Acesso em: 27 maio 2009.

DAMÁSIO, A. O erro de Descartes: emoção, razão e cérebro humano. 22. ed. Europa-América, 2001.

DAOLIO, J. Jogos esportivos coletivos: dos princípios operacionais aos gestos técnicos: modelo pendular a partir das idéias de Claude Bayer. Rev Bras Cien Mov, v. 10, n. 4, p. 99-104, 2002. Disponível em: http://portalrevistas.ucb.br/. Acesso em: 10 maio 2009.

DURWARD, B.; BAER, G.; ROWE, P. Movimento funcional humano. São Paulo: Manole, 2001.

ESPOSITO, F. et al. Validity of heart rate as an indicator of aerobic demand during soccer activities in amateur soccer player. Eur J Appl Physiol, v. 93, n. 1-2, p. 167-172, 2004.

FARIA, R.; FRADE, V. Periodização tática: um imperativo conceito metodológico do rendimento superior em futebol. 1999. Monografia (Trabalho de Conclusão de Curso) - Faculdade de Ciências do Desporto e Educação Física, Universidade do Porto, Porto, 1999.

FERRARI, E. et al. Plasticidade neural: relação com o comportamento e abordagem experimentais. Psicol: teor pesqu, v. 17, n. 2, p. 187-94, 2001. Disponível em: www.scielo.br. Acesso em: 4 jun. 2008.

FILGUEIRA, F.; GRECO, P. Futebol: um estudo sobre a capacidade tática no processo de ensinoaprendizagem-treinamento. Rev Bras Futebol, v. 1, n. 2, p. 53-65, 2008. Disponível em: www.rbfutebol.com.br. Acesso em: 3 maio 2009.

FRADE, V. Alta competição no futebol: que exigências de tipo metodológico? Porto: ISEF:Universidade do Porto, 1985. (Curso de Atualização).

FREIRE SILVA, T.; DE ROSE JUNIOR, D. Iniciação nas modalidades esportivas coletivas. Rev Educ Fis Esp, v. 4, n. 4, p. 71-93, 2005. Disponível em: www.mackenzie.br/remef.html. Acesso em: 29 maio 2009.

Conexões: revista da Faculdade de Educação Física da UNICAMP, Campinas, v. 7, n. 2, p.38-63, maio/ago. 2009. 


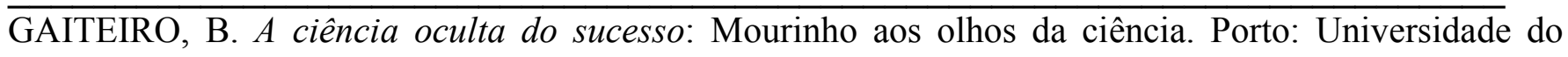
Porto, 2006.

GARGANTA, J. Modelação tática do jogo de futebol: estudo da organização da fase ofensiva em equipas de alto rendimento. 1997. Tese (Doutorado) - Faculdade de Ciências do Desporto e Educação Física, Universidade do Porto, Porto, 1997.

. La prestacion energetico funzionale del calciatore. Teknosport, v. 11, p.18-27, 1999.

. O treino da tática e da técnica nos jogos desportivos à luz do compromisso cognição-ação. In: BARBANTI, V.; AMADIO, A.; BENTO, J.; MARQUES, A. (Org.). Esporte e atividade física: interação entre rendimento e saúde. São Paulo: Manole, 2002. p. 281-306.

. Futebol e ciência: ciência e futebol. Lecturas: EF y Deportes, Revista Digital. 2001. Disponível em: www.efdeportes.com/. Acesso em: 15 de fev. 2004.

. (Re)Fundar os conceitos de estratégia e tática nos jogos desportivos coletivos, para promover uma eficácia superior. Rev Bras Educ Fís Esp, v. 20, n. S5, p. 201-203, 2006. Disponível em: www.usp.br/eef/. Acesso em: 27 de fev. 2007.

. O ensino dos jogos desportivos coletivos. Perspectivas e tendências. Mov, v. 4, n. 8, p. 19-26, 1998. Disponível em: www.seer.ufrgs.br/index.php/index. Acesso em: 28 de maio 2009.

.; GRÉHAIGNE, J. Abordagem sistêmica do jogo de futebol: moda ou necessidade? Mov, v. 5, n. 10, p. 40-50, 1999. Disponível em: www.seer.ufrgs.br/index.php/index. Acesso em: 4 de jun. 2009.

.; MAIA, J.; MARQUES, A. Acerca da investigação dos fatores de rendimento em futebol. Rev Paul Educ Fís, v. 10, n. 2, p. 146-158, 1996.

GARGANTA, J.; CUNHA E SILVA, P. O jogo de futebol: entre o caos e a regra. Rev Horiz, v. 16, n. 91, p. 5-8, 2000.

GASPAR, P.; FERREIRA, J.; PÉREZ, L. Tomada de decisão no desporto: o seu ensino em jovens atletas. Rev Mackenzie Educ Fís Esp, v. 4, n. 4, p. 95-111, 2005. Disponível em: www.mackenzie.br/remef.html. Acesso em: 28 de maio 2009.

GAYA, A.; TORRES, L.; BALBINOTTI, C. Iniciação esportiva e a educação física escolar. In: SILVA, F. (Org.). Treinamento desportivo: aplicações e implicações. João Pessoa: UFPB, 2002. p. 15-25.

GAUFFIN, H.; EKSTRAND, J.; TROPP, H. Improvement of vertical jump performance in soccer players after specific training. J Hum Mov Studies, v. 15, p. 185-190, 1988.

GRÉHAIGNE, J-F.; GODBOUT, P.; BOUTHIER, D. The teaching and learning of decision making in team sports. Quest, v. 53, n. 1, p. 59-76, 2001. 
GOMES, M. Do pé como técnica ao pensamento técnico dos pés dentro da caixa preta da periodização tática: um estudo de caso. Porto: FCDEF, 2006.

GRAÇA, A. Os comos e os quandos no ensino dos jogos. In: GRAÇA, A.; OLIVEIRA, J. (Ed.). O ensino dos jogos desportivos. Porto: FCDEF: UP, 1994. p. 27-34.

.; MESQUITA, I. A investigação sobre os modelos de ensino dos jogos desportivos. Rev Port Ciên Desp, v. 7, n. 3, p. 401-421, 2007. Disponível em: www.fade.up.pt/rpcd. Acesso em: 29 maio 2009. GRECO, P. Conhecimento tático-técnico: eixo pendular da ação tática (criativa) nos jogos esportivos coletivos. Rev Bras Educ Fis Esp, v. 20, n. S5, p. 210-212, 2006. Disponível em: www.usp.br/eef/. Acesso em: 28 maio 2009.

HUGHES, M.; FRANKS, I. Analysis of passing sequences, shots and goals in soccer. $J$ Sports Sci, v. 23, n. 5, p. 509-514, 2005.

JENSEN, J.; MARSTRAND, P.; NIELSEN, J. Motor skill training and strength training are associated with different plastic changes in the central nervous system. J Appl Physiol, v. 99, n. 4, p. 1558-1568, 2005. Disponível em: www.jap.org. Acesso em: 3 jun. 2009.

KRÖGER, C.; ROTH, K. Escola da bola. São Paulo: Phorte, 2002.

LEBED, F. System approach to games and competitive playing. Eur J Sport Sci, v. 6, n. 1, p. 33-42, 2006.

LEAL, J. C. Futebol: arte e ofício. 2. ed. Rio de Janeiro: Sprint, 2001.

LEITÃO, A. Futebol: análise qualitativa e quantitativa para verificação e modulação de padrões e sistemas complexos de jogo. 2004. Dissertação (Mestrado em Educação Física) - Faculdade de Educação Física, Universidade Estadual de Campinas, Campinas, 2004. Disponível em: http://libdigi.unicamp.br. Acesso em: 22 nov. 2007.

. A velocidade tática e as fases sensiveis do desenvolvimento atlético. Universidade do Futebol: Colunas Táticas, 2008. Disponível em: http://universidadedofutebol.com.br/. Acesso: 03 jun. 2009. . Se jogo é jogo e treino é treino, abandonemos os treinos (e fiquemos com o jogo!). Universidade do Futebol: Colunas Táticas, 2008b. Disponível em: http://www.universidadedofutebol.com.br/. Acesso: 03 jun. 2009.

LEONARDO, L.; SCAGLIA, A.; REVERDITO, R. O ensino dos esportes coletivos: metodologia pautada na família dos jogos. Motriz, v. 15, n. 2, p. 236-246, 2009. Disponível em: http://cecemca.rc.unesp.br/ojs/index.php/motriz. Acesso em: 27 maio 2009.

MAGUEIJO, J. Mais rápido que a luz: a bibliografia de uma especulação científica. Lisboa: Gradiva, 2003.

Conexões: revista da Faculdade de Educação Física da UNICAMP, Campinas, v. 7, n. 2, p.38-63, maio/ago. 2009. 
MATTA, M.; GRECO, P. O processo de ensino-aprendizagem-treinamento da técnica esportiva aplicada ao futebol. Rev Min Educ Fís, v. 4, n. 2, p. 34-50, 1996.

MARTINS, F.; GARGANTA, J. "Periodização tática" segundo Vitor Frade: mais do que um conceito, uma forma de estar e de reflectir o futebol. 2003. Monografia (Trabalho de Conclusão de Curso) Faculdade de Ciências do Desporto e Educação Física, Universidade do Porto, Porto, 2003.

MARQUES JUNIOR, N. K. Solicitação metabólica no futebol profissional masculino e o treinamento cardiorrespiratório. Corpoconsciência, Santo André, n. 13, p. 25-58, 2004.

. Periodização tática: uma nova organização do treinamento para duplas masculinas do voleibol na areia de alto rendimento. Rev Min Educ Fís, v. 14, n. 1, p. 46-65, 2006.

. Periodização tática: o treinamento de iniciadas do futebol de salão feminino. Mov Percep, v. 8, n.

11, p. 7-41, 2007. Disponível em: www.unpinhal.edu.br/movimentopercepcao. Acesso em: 30 dez. 2007.

. Ensino do treino da visão periférica para jogadores do futsal. Rev Bras Ed Fis Esp Lazer e Dança, São Paulo, v. 4, n. 1, p. 34-52, 2009. Disponível em: www.refeld.com.br. Acesso em: 18 maio 2009.

. Fundamentos praticados pelo defensor durante o jogo de voleibol na areia. Conexões, Campinas, v. 7, n. 1, p. 61-71, 2009b. Disponível em: www.unicamp.br/fef/. Acesso em: 01 abr. 2009.

MOIGNE, J. O construtivismo dos fundamentos. Lisboa: Instituto Piaget, 1994.

MORIN, E. Introdução ao pensamento complexo. 3. ed. Lisboa: Instituto Piaget, 1990.

. O método I: a natureza da natureza. 3. ed. Publicações Europa América, 1997.

. Reformar o pensamento: a cabeça bem feita. Lisboa: Instituto Piaget, 1999.

. Introdução ao pensamento complexo. 4. ed. Lisboa: Instituto Piaget, 2003.

NUNES, J.; FANTATO, E.; MONTAGNER, P. C. Velocidade no basquetebol. Conexões, Campinas, v. 4, n. 2, p. 47-54, 2006. Disponível em: www.unicamp.br/fef/. Acesso em: 06 jun. 2009.

OLIVEIRA, J. Organização do jogo de uma equipa de Futebol. Aspectos metodológicos na abordagem da sua organização estrutural e funcional. In: JORNADAS TÉCNICAS DE FUTEBOL + FUTSAL DA UTAD, 2., 2003. Anais... Vila Real: UTAD, 2003.

. Futebol/Futsal: uma concepção de treino, periodização tática. Porto: Faculdade de Ciências do Desporto e Educação Física, 2004.

.; FRADE, V. Especificidade, o "pós-futebol" do "pré-futebol": um fator condicionante do alto rendimento desportivo. 1991. Monografia (Trabalho de Conclusão de Curso) - Faculdade de Ciências do Desporto e Educação Física, Universidade do Porto, Porto, 1991.

OLIVEIRA, B. et al. Mourinho: porquê tantas vitória? Lisboa: Gradiva, 2006.

Conexões: revista da Faculdade de Educação Física da UNICAMP, Campinas, v. 7, n. 2, p.38-63, maio/ago. 2009. 
$\overline{\text { OLIVEIRA, P. R.; AMORIM, C.; GOULART, L. Estudo do esforço físico no futebol júnior. Rev }}$ Par Educ Fís, v. 1, n. 2, p. 49-58, 2000.

OLIVEIRA, R. A planificação, programação e periodização do treino em futebol. Lecturas: EF y Deportes, Revista Digital. 2005. Disponível em: www.efdeportes.com/. Acesso em: 07 out. 2004.

. O microciclo de treino: a base fundamental da planificação tático-estratégica de um jogo de futebol. Lecturas: EF y Deportes, Revista Digital. 2007. Disponível em: www.efdeportes.com/. Acesso em: 02 jun. 2007.

PAPADIMITRIOU, K. et al. Evaluation of the offensive behavior of elite soccer teams. Percept Mot Skills, v. 93, n. 2, p. 405-415, 2001.

PÉREZ MORALES, J.; GRECO, P. A influência de diferentes metodologias de ensino-aprendizagemtreinamento no basquetebol sobre o nível de conhecimento tático processual. Rev Bras Educ Fis Esp, São Paulo, v. 21, n. 4, p. 291-299, 2007. Disponível em: www.usp.br/eef/. Acesso em: 28 maio 2009.

PRILUTSKY, B.; ZATSIORSKY, V. Tendon action of two-joint muscles. J Biomech, v. 27, n. 1, p. 2534, 1994.

RAAB, M. Decision making in sports. Int J Sport Exerc Psychol, v. 1, n. 2, p. 310-337, 2003.

. Think Smart, not hard, a review of teaching decision making in sport from an ecological rationality perspective. Physic Educ Sport Pedag, v. 12, n. 1, p. 1-15, 2007.

RAAB, M.; MASTERS, R.; MAXWELL, J. Improving the how and what decision of elite table tennis players. Hum Mov Sci, v. 24, p. 326-344, 2005.

RAHNAMA, N.; REILLY, T.; LEES, A. Injury risk associated with playing actions during competitive soccer. Br J Sports Med, v. 36, n. 5, p. 354-359, 2002. Disponível em: www.bjsportmed.com. Acesso em: 30 dez. 2007.

RAMOS, L.; OLIVEIRA JUNIOR, M. Futebol: classificação e análise dos gols da EuroCopa 2004. Rev Bras Futebol, v. 1, n. 1, p. 42-48, 2008. Disponível em: www.rbfutebol.com.br. Acesso em: 30 dez. 2007. RÉ, A.; BARBANTI, V. Uma visão macroscópica da influência das capacidades motoras no desempenho esportivo. In: RIGOLIN DA SILVA, L. (Ed.). Desempenho esportivo: treinamento com crianças e adolescentes. Rio de Janeiro: Phorte, 2006. p. 217-240.

REILLY, T. Assessment of sport performance with particular reference to field games. Eur J Sport Sci, v. 1, n. 3, p. 1-12, 2001.

.; GILBOURNE, D. Science and football: a review of applied research in the football codes. $J$ Sports Sci, v. 21, p. 693-705, 2003.

Conexões: revista da Faculdade de Educação Física da UNICAMP, Campinas, v. 7, n. 2, p.38-63, maio/ago. 2009. 
RINK, J.; FRENCH, K.; TJEERDSMA, B. Foundations for the learning and instruction of sport and games. J Teach Physic Educ, v. 15, n. 4, p. 399-417, 1996.

ROBERTSON, E.; PASCUAL-LEONE, A.; MIALL, R. Current concepts in procedural consolidation. Nature Rev, v. 5, p. 1-7, 2004.

SANTOS, P.; SILVA, P.; JARDIM, N. O remate de futebol: caracterização biomecânica e considerações para o treino de força rápida. Lecturas: EF y Deportes, Revista Digital. 2004. Disponível em: www.efdeportes.com/. Acesso em: 24 jun. 2004.

. O planeamento e a periodização do treino em futebol: um estudo realizado em clubes da Superliga. 2006. Dissertação (Mestrado) - Universidade Técnica de Lisboa, Lisboa, 2006. Disponível em: http://educacaofisica.seed.pr.gov.br. Acesso em: 10 dez. 2008.

SCAGLIA, A. O futebol e os jogos/brincadeiras de bola com os pés: todos semelhantes, todos diferentes. 2003. Tese (Doutorado em Educação Física) - Faculdade de Educação Física, Universidade Estadual de Campinas, Campinas, 2003. Disponível em: http://libdigi.unicamp.br. Acesso em: 04 jun. 2009.

SILVA, A. et al. Patrones de juego en el fútbol de alto rendimiento análisis secuencial del proceso ofensivo en el Campeonato del Mundo Corea-Japón 2002. Cult Cien Desp, v. 1, n. 2, p. 65-72, 2005. Disponível em: www.ucam.edu/ccd. Acesso em: 20 dez. 2008.

SILVA, P. A análise do jogo em futebol: um estudo realizado em clubes da Liga Betandwin.com. 2006. Dissertação (Mestrado) - Faculdade de Motricidade Humana, Lisboa, 2006. Disponível em: http://educacaofisica.seed.pr.gov.br. Acesso em: 10 dez. 2008.

SINDIK, J.; VIDAK, N. Application of game theory in describing efficacy of decision making in sportsman`s tactical performance in team sports. Interdisciplinary Description of Complex Systems, v. 6, n. 1, p. 53-66, 2008.

TAMARIT, X. Qué es la periodización táctica? España: MC Sport, 2007.

TAVARES, J.; FRADE, V. Uma noção fundamental: a especificidade, como investigar a ordem das "coisas" do jogar, uma espécie de invariâncias de tipo fractal. 2003. Monografia (Trabalho de Conclusão de Curso) - Faculdade de Ciências do Desporto e Educação Física, Porto, 2003.

TAVARES, F. Análise da estrutura e dinâmica do jogo nos jogos desportivos. In: BARBANTI, V.; AMADIO, A.; BENTO, J.; MARQUES, A. (Org.). Esporte e atividade física: interação entre rendimento e saúde. São Paulo: Manole, 2002. p. 129-143.

TELES, A. Conhecimento tático declarativo e procedimental em crianças e adolescentes praticantes de futebol. 2007. Dissertação (Mestrado) - Universidade Federal de Pernambuco, Pernambuco, 2007. 
TRNINIC, S. et al. Player selection procedures in team sports games. Acta Kinesiol, v. 2, n. 1, p. 24-28, 2008.

TUBINO, M.; MOREIRA, S. Metodologia científica do treinamento desportivo. 13. ed. Rio de Janeiro: Shape, 2003.

TURATO, M. Tratado metodológico da pesquisa clínico-qualitativa. 2. ed. Petrópolis: Vozes, 2003.

TURNER, A.; MARTINEK, T. Teaching for understand: a model for improving decision making during game play. Quest, v. 47, n. 1, p. 44-63, 1995.

WILLIAMS, M.; HODGES, N. Practice, instruction and skill acquisition in soccer: challenging. $J$ Sports Sci, v. 23, n. 6, p. 637-650, 2005.

WALDROP, M. Complexity: the emerging science at the edge of order and chaos. New York: Touchstone, 1992.

WOLPERT, D.; GHAHRAMANI, Z.; FLANAGAN, J. Perspective and problems in motor learning. Trends Cogn Sci, v. 5, n. 11, p. 487-494, 2001. 


\section{Pedro Miguel Silva}

Faculdade de Motricidade Humana, Lisboa, Portugal

\section{Pedro Manuel de Oliveira Santos \\ Universidade de Vigo, Espanha}

\section{Nelson Kautzner Marques Júnior}

Universidade Castelo Branco

\section{Referência do artigo}

\section{ABNT}

SILVA, P. M.; SANTOS, P. M. O.; MARQUES JUNIOR, N. K. Treinar futebol respeitando a essência do jogo: o exemplo do salto como ação tática e não somente técnico-físico. Conexões, v. 7, n. 2, p. 38-63, 2009.

\section{APA}

Silva, P. M., Santos, P. M. O., \& Marques Junior, N. K. (2009). Treinar futebol respeitando a essência do jogo: o exemplo do salto como ação tática e não somente técnico-físico. Conexões, 7(2), 38-63.

\section{VANCOUVER}

Silva PM, Santos PMO, Marques Junior NK. Treinar futebol respeitando a essência do jogo: o exemplo do salto como ação tática e não somente técnico-físico. Conexões, 2009; 7(2): 38-63.

Recebido em: 04/03/2009

Aceito para publicação em: jun./2009 